\title{
Assessing Energy Efficiency of Compression Heat Pumps in Drying Processes when Zeotropic Hydrocarbon Mixtures are Used as Working Agents
}

\author{
Alexander Shurayts ${ }^{1}$, Alexander Rulev ${ }^{2, *}$, and Elena Usacheva ${ }^{3}$ \\ ${ }^{1}$ Yuri Gagarin State Technical University of Saratov, 410054, st. Politechnicheskaya, Saratov, \\ Russian Federation \\ ${ }^{2}$ Public Limited Company “Giproniigaz”, 410012, st.Kirova, Saratov, Russian Federation \\ ${ }^{3}$ Scientific Technologies Ltd, 410062, st. Moscow highway, Saratov, Russian Federation
}

\begin{abstract}
Presents the results of studies of innovative materials in the field of renewable energy.The paper proposes a design and a formula for assessing energy efficiency of the heat pump air dryer, which uses zeotropic hydrocarbon mixtures of saturated hydrocarbons as a working agent and applies the principle of a counter-current heat exchanger with a variable temperature of both the working and the drying agents. Energy efficiency of the heat pump is achieved by means of obtaining a greater part of heat from renewable energy sources, in this case by cooling the air and condensing the water vapors in the heat pump. A conducted analysis identified correlations in establishing the marginal real coefficient of performance of the compression heat pump dryer running on zeotropic hydrocarbon mixtures and operating a cycle with variable temperatures of both the working and the drying agent in the evaporator and the condenser of the heat pump. According to the established correlations, the marginal real coefficient of performance of the compression heat pump dryers running on zeotropic hydrocarbon mixtures of $40 \mathrm{~mol} \%$ of R600a and 60 mol\% of R601 is 1.92 times higher than that of the same dryers running on only R600 (n-butane).
\end{abstract}

\section{Introduction}

Drying agricultural and other types of produce, including grassy forage, vegetables, fruits, grains, timber, pottery and other materials, accounts for a significant energy consumption.

A literature review [1-5] demonstrates that grassy forage, grains, vegetables, fruits, different types of timber, and other materials are dried most properly and effectively with heat pumps at low temperatures using the air as the drying agent with its complete recirculation and dehydration. Energy efficiency of the heat pump is achieved by means of obtaining heat from a renewable energy source, in this case by cooling the air and condensation of water vapors in the heat pump. According to $[1,5,6]$, the average rate of

* Corresponding author: ritamitrofanova@yandex.ru 
return of such installations is 3-4 years. An optimal type of engine for the compressor of the industrial heat pump dryer is a gas engine [1], which allows for a considerable increase in the combustion efficiency of the primary fuel by means of useful heat extraction from flue gases, condensation of water vapors in them, and the use of heat from cooling systems and engine lubrication. Existing types of heat pumps use substances with a constant boiling point as a working agent, which is not energy efficient when low-temperature heat sources, such as ground and outdoor bodies of water, have a high volumetric heat capacity $[1,2,4]$, and therefore their temperature remains constant or varies slightly.

At the same time, when a source or sink for heat has limited volumetric heat capacity, for example, the drying air [7], whose temperature changes significantly while it is being dehydrated in the evaporator and being heated in the condenser, using a substance with a constant boiling point as a working agent $[8,9]$ is characterized by reduced efficiency of non-renewable energy (electricity from thermal power plants, gas, etc.) used to drive the compressor.

\section{Heat pump dryer design concept and description}

The proposed design of the heat pump dryer that applies a complete recirculation of air and runs a cycle with variable temperatures of both the working and the drying agents that flow in opposite directions, is an energy efficient drying solution (fig. 1).

The design concept is as follows. The working agent chosen is a two-component zeotropic mixture 4, which, when boiled in evaporator 1 , increases its temperature from the initial value at the inlet of evaporator tubes unit 3 to the final temperature value at the outlet. Contrary to that, humid air 5, while flowing throw shell side 2 in the opposite direction, reduces its temperature from the initial value at the outlet to the final temperature value at the inlet of evaporator tubes unit 3. During its transition from vapor to liquid in condenser 9, the zeotropic mixture reduces its temperature from the initial value at the inlet to condenser tubes unit 11 to the final value at the outlet. Contrary to that, dehumidified air 5, flowing throw shell side 10 in the opposite direction, increases its temperature from its initial value, at the outlet, to the final value at the inlet to condenser tubes unit 11 . The change in the temperature of boiling and condensation of the zeotropic mixture, as well as the change in the value of the temperature difference of the beginning and end of boiling or condensation, can be achieved by changing the percent composition of one of its components. Figure 1 shows the design and the operating principles of the gas engine heat pump.

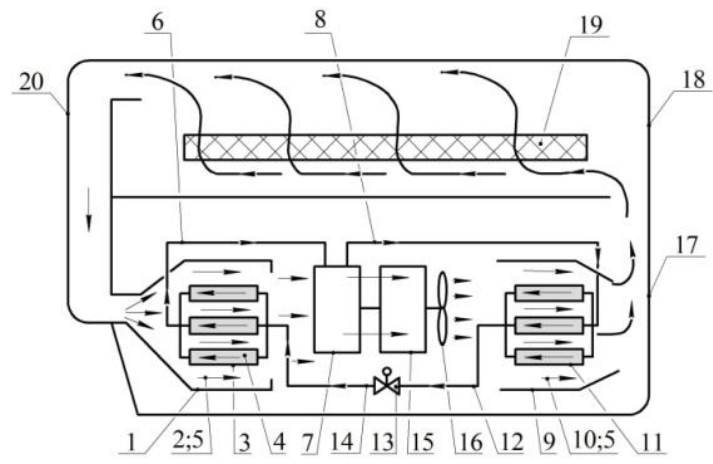

Fig. 1. Design of the heat pump dryer running on a zeotropic hydrocarbon mixture with a gas engine drive: 1 - evaporator; 2 - evaporator shell side; 3 - evaporator tubes unit; 4 - working agent made from a two-component zeotropic mixture; 5 - air; 6 - tubes of the vapor phase of working agent 4 used to connect to the outlet of evaporator tubes unit 3; 7 - compressor; 8 - tubes of the vapor phase of working agent 4 used to connect to the outlet of compressor $7 ; 9-$ condenser; $10-$ 
condenser 9 shell side; 11 - condenser tubes unit; 12 - tubes of the liquid phase of working agent 4 used to connect to the outlet of condenser tubes unit $11 ; 13$ - temperature regulator reducing the temperature of the saturated liquid phase of working agent $4 ; 14$ - tubes of the liquid phase of working agent 4 connecting regulator 13 with the inlet of evaporator tubes unit $3 ; 15-$ gas engine to drive the compressor; 16 - fan; 17 - heat pump station; 18 - drying station; 19 - drying products; 20 - recirculation duct.

\section{Selection of the working agent}

Working substances used as components of a zeotropic mixture in heat pump dryers should not contribute to the depletion of the ozone layer of the atmosphere [10] and climate change [11], should be fireproof and cost-efficient, available for use and have no negative impact on the human body, they should have variable values of boiling points and condensation, which are the most suitable for the drying process of grass, grain and similar products. Currently, there are no working agents that can perfectly satisfy all these requirements. For example, freons R11, R12, R22 widely used in the past, which satisfy the low-temperature drying conditions of agricultural and other similar products and could be used as components of a zeotropic mixture in heat pump dryers, have negative effects on the ozone layer of the atmosphere and contribute to climate change. In this respect, the choice of components for the zeotropic mixture is carried out individually, relevant to the lowtemperature heat pump air dryer considering all positive and negative factors of their effect.

Based on the results of the conducted analysis, zeotropic mixtures of saturated hydrocarbons, consisting of R600a (isobutane) and R601 (n-pentane) meet these requirements more fully. R600a and R601 are considered to be completely safe in terms of their effect on the ozone layer of the Earth. These gases do not cause the greenhouse effect, do not have affect climate change or the human body, are extracted directly from natural gas, and are much cheaper than other working agents.

However, using zeotropic mixtures can result in a reduced heat emission coefficient in "the inner surface of the heat exchange tubes unit - the working agent" system of the evaporator and the condenser of the heat pump (fig. 1) due to reduced vaporization centers and decreased bubble departure diameter, compared to each of the components of the mixture [12]. The calculations, carried out in accordance with [12-14], demonstrate that the reduction of the overall heat emission coefficient does not exceed $5.5 \%$, since the main specific weight in the total balance of its value takes the heat emission coefficient in "the outer surface of the finned heat exchanger tubes unit — the drying air" system, which is characterized by relatively low heat emission in case of forced air flow. Such heat emission reduction rate and a subsequent increase in capital investment in heat exchange surfaces of the evaporator and the condenser in this case are as not as significant as the reduced operating costs due to an increased coefficient of compression heat pump dryer performance, which is explained below.

The drawback of saturated hydrocarbons, when used as components of zeotropic mixtures, is that they pose a fire hazard. In this respect, industrial heat pump dryers should be equipped with smoke detectors. At the same time, when used as a drive for the compressor of the gas engine, which is most preferred in the drying process, a smoke detector is mandatory, based on the security requirements for gas supply items $[15,16]$. Apart from that, in the case of modern heat pump dryers with a small filling capacity (35-50 $\mathrm{g})$, even if the entire working agent leaks out, its concentration in a space of $15 \mathrm{~m} 3$ will be ten or more times lower than $1.7-1.35 \%$, the lowest inflammability limit of R600a and R601 mixtures [17,18]. Given the overall balance of advantages and disadvantages, currently more than $35 \%$ of household refrigerators in Europe run on isobutane R600a. The low-boiling component of the mixture, R600a has the boiling point of $\mathrm{t}=-11.73^{\circ} \mathrm{C}$ in the 
atmospheric pressure and the high-boiling component R601 has the temperature of $\mathrm{t}=$ $+36.07^{\circ} \mathrm{C}$.

Now we estimate the change of temperature conditions for the heat pump, designed for air drying, operating on a zeotropic mixture of R600a (isobutane) and R601 (n-pentane), containing $40 \mathrm{~mol} \%$ of R600a.

\section{Estimating temperature conditions of the working and the drying agents}

In order to estimate temperature conditions of the heat pump, we need to know the following:

1) change in the current temperature of the saturated zeotropic mixture of R600a and R601 in the evaporator and the condenser of the heat pump, including its initial and final values, in relation to the degree of dryness $\mathrm{X}$ in the variation range from 0 to 1 ;

2) change in the temperature of the drying air in the evaporator and the condenser of the heat pump, including its initial and final values, in relation to the temperature and flow volume of the saturated zeotropic mixture.

The nature of temperature $t$ changes in the evaporator and the condenser of the heat pump, including its initial and final values for the zeotropic mixture of R600a and R601, for which Dalton's law, Raoult's law [17,18], Konovalov's first law [19], the Antoine equation $[20,21]$ for saturated vapor pressure for pure components are applicable, can be estimated depending on the degree of dryness X, according to [20]:

$$
\begin{aligned}
& X=P_{m}\left(\frac{\psi}{\beta}+\frac{1-\psi}{\xi}\right) \\
& \beta=\left(P_{m}-10^{A_{R 601}-\frac{B_{R 601}}{C_{R 601}+t}}\right) \\
& \xi=\left(P_{m}-10^{A_{R 600 a}-\frac{B_{R 600 a}}{C_{R 600 a}+t}}\right)
\end{aligned}
$$

where: $\mathrm{Pm}$ is the absolute total pressure of the mixture, $\mathrm{Pa} 105 ; \psi$ is the R600a content in the initial liquid and vapor phases of the mixture, with which it enters the evaporator and the condenser of the heat pump, mol.\%; AR600a, BR600a, CR600a , AR601, BR601, CR601 are coefficients typical for saturated hydrocarbons R600a and R601 within a certain temperature range; $\mathrm{t}$ is the boiling point of an individual hydrocarbon (R600a and $\mathrm{R} 601),{ }^{\circ} \mathrm{C}$.

Based on the most accurate experimental data on the saturated hydrocarbons R600a and R601, [21, 22] gives the coefficients AR600a, BR600a, CR600a, AR601, BR601, CR601 in formulas (2) and (3). Differences, resulting from applying calculation formulae (1)-(3) based on Dalton's laws, Raoult's law and the Antoine equation for zeotropic mixtures of saturated hydrocarbons at the absolute pressure up to $1.0 \mathrm{MPa}$, to the actual measurement data, are $4.5 \%$ [23].

Changes in the temperature of evaporated and condensed mixture in the range of the dryness degree $\mathrm{X}$ from 0 to 1.0 result in a change in the temperature of the heated or cooled drying air. The initial temperature value of a limited heat capacity environment, in this case 
the air, depending on the temperature changes, dryness factor and the zeotropic mixture flow rate, for the case of the counter-current heat exchanger, is determined from the balance equation between the working and drying agents in the evaporator and the condenser of the heat pump.

For the heat pump evaporator:

$$
\mathrm{T}_{\mathrm{ai} . \mathrm{i}}^{\mathrm{v}}=\frac{\mathrm{G}_{\mathrm{ai}} \mathrm{c}_{\mathrm{ai}}^{\mathrm{v}} \mathrm{T}_{\mathrm{a} . \mathrm{f}}^{\mathrm{v}}+\mathrm{G}_{\mathrm{m}}\left[\mathrm{r}_{\mathrm{m}}^{\mathrm{v}} \mathrm{X}_{\mathrm{m}}^{\mathrm{v}}+\mathrm{c}_{\mathrm{m}}^{\mathrm{v}}\left(\mathrm{T}_{\mathrm{m} . \mathrm{f}}^{\mathrm{v}}-\mathrm{T}_{\mathrm{m} . \mathrm{i}}^{\mathrm{v}}\right)\right]}{\mathrm{c}_{\mathrm{ai}}^{\mathrm{v}} \mathrm{G}_{\mathrm{ai}}} .
$$

For the heat pump condenser:

$$
\mathrm{T}_{\mathrm{a} . \mathrm{i}}^{\mathrm{c}}=\frac{\mathrm{G}_{\mathrm{ai}} \mathrm{c}_{\mathrm{ai}}^{\mathrm{c}} \mathrm{T}_{\mathrm{ai} . \mathrm{f}}^{\mathrm{c}}-\mathrm{G}_{\mathrm{m}}\left[\mathrm{r}_{\mathrm{m}}^{\mathrm{c}} \mathrm{X}_{\mathrm{m}}^{\mathrm{c}}+\mathrm{c}_{\mathrm{m}}^{\mathrm{c}}\left(\mathrm{T}_{\mathrm{m} . \mathrm{i}}^{\mathrm{c}}-\mathrm{T}_{\mathrm{m} . \mathrm{f}}^{\mathrm{c}}\right)\right]}{\mathrm{c}_{\mathrm{ai}}^{\mathrm{c}} \mathrm{G}_{\mathrm{ai}}} .
$$

where: $\mathrm{T}_{\text {ai.i }}^{\mathrm{v}}, \mathrm{T}_{\text {ai.f }}^{\mathrm{v}}$ are the initial and final temperatures of the drying air in the evaporator, $\mathrm{K}$; $\mathrm{T}_{\mathrm{m} . \mathrm{f}}^{\mathrm{v}}, \mathrm{T}_{\mathrm{m} . \mathrm{i}}^{\mathrm{v}}$ are the initial and final temperatures of the zeotropic mixture in the evaporator, $\mathrm{K} ; \mathrm{T}_{\mathrm{ai.f}}^{\mathrm{c}}, \mathrm{T}_{\mathrm{ai.i}}^{\mathrm{c}}$ are final and initial temperatures of the drying air in the condenser, $\mathrm{K}$; $\mathrm{T}_{\mathrm{m} . \mathrm{i}}^{\mathrm{c}}, \mathrm{T}_{\mathrm{m} . \mathrm{f}}^{\mathrm{c}}$ are initial and final temperatures of the zeotropic mixture in the condenser, $\mathrm{K}$; $\mathrm{G}_{\mathrm{m}}, \mathrm{G}_{\mathrm{ai}}$ are the mole discharge of the zeotropic mixture and the drying air, mol/h; $\mathrm{r}_{\mathrm{m}}^{\mathrm{v}}, \mathrm{r}_{\mathrm{m}}^{\mathrm{c}}$ are the average values of latent heat of evaporation (vaporization) of the zeotropic liquidvapor mixture in the condenser and the evaporator, $\mathrm{kJ} / \mathrm{mol} ; \mathrm{c}_{\mathrm{ai}}^{\mathrm{v}}, \mathrm{c}_{\mathrm{ai}}^{\mathrm{c}}$ are mean specific heat of the drying air in the evaporator and the condenser, $\mathrm{kJ} /(\mathrm{mol} \cdot \mathrm{K}) ; \mathrm{c}_{\mathrm{m}}^{\mathrm{v}}, \mathrm{c}_{\mathrm{m}}^{\mathrm{c}}$ are mean specific heat of zeotropic liquid-vapor mixture in its boiling and condensation temperature intervals in the evaporator and the condenser, $\mathrm{kJ} /(\mathrm{mol} \cdot \mathrm{K}) ; \mathrm{X}_{\mathrm{m}}^{\mathrm{v}}, \mathrm{X}_{\mathrm{m}}^{\mathrm{c}}$ are the dryness factor of the zeotropic mixture in the evaporator and the condenser, unit fractions.

Estimating the temperatures of the zeotropic mixture and the drying air at given $\mathrm{X}$ is carried out using the formulae (1)-(3) and applying the method of successive approximations in the following manner.

1. We shall assume that the concentration value of R600a and R601 in the zeotropic mixture equals $40 \mathrm{~mol} . \%$.

2. The temperature of the drying air in the condenser outlet considering low temperature drying conditions equals $\mathrm{t}_{\mathrm{ai} . \mathrm{f}}^{\mathrm{c}}=65^{\circ} \mathrm{C}$. The initial and final temperature values are shown in the figure "temperature (T) - entropy (S)", (fig. 2). Since the temperatures in the T-S diagram are indicated in Kelvin degrees, the following notation and value will be applied: $\mathrm{T}_{\mathrm{ai} . \mathrm{f}}^{\mathrm{c}}=338 \mathrm{~K}$.

Assume the initial temperature drop between heat exchange streams at the inlet of the counter-current condenser is at a rate of $\Delta \mathrm{t}=7{ }^{\circ} \mathrm{C}$. Then the initial temperature for zeotropic mixture of R600a and R601 in the condenser will be $\mathrm{t}_{\mathrm{m} . \mathrm{i}}^{\mathrm{c}}=\mathrm{t}_{\text {ai.f }}^{\mathrm{c}}+\Delta \mathrm{t}=65+7=72$ ${ }^{0} \mathrm{C}\left(\mathrm{T}_{\mathrm{m} . \mathrm{i}}^{\mathrm{c}}=345 \mathrm{~K}\right)$. Then, according to the formulae (1)-(3), taking the values of $\mathrm{X}=1$ (beginning of condensation of the saturated vapor phase), $\mathrm{t}_{\mathrm{m} . \mathrm{i}}^{\mathrm{c}}=72{ }^{0} \mathrm{C}$ and $\psi=40 \mathrm{~mol} \%$ of 
R600a, by the trial method we estimate the absolute pressure, whose value, based on the results of calculations, equals $\mathrm{P}_{\mathrm{m}}^{\mathrm{c}}=0.4 \mathrm{MPa}$.

3. The final temperature value of the mixture in the condenser is estimated using the formulae (1)-(3) and applying the trial method with the value of $X=0$ (end of condensation of the saturated vapor phase) and $\mathrm{P}_{\mathrm{m}}^{\mathrm{c}}=0.4 \mathrm{MPa}$, whose value equals $\mathrm{t}_{\mathrm{m} . \mathrm{f}}^{\mathrm{c}}=$ $550 \mathrm{C}\left(\mathrm{T}_{\mathrm{m} . \mathrm{f}}^{\mathrm{c}}=328 \mathrm{~K}\right)$ (fig. 2).

4. Further, according to the formula (5), for the case of the counter-current heat exchanger (fig. 2), we estimate the drying air temperature in the condenser inlet, in relation to the temperature change and the zeotropic mixture flow, which is $\mathrm{T}_{\text {ai. } \mathrm{i}}^{\mathrm{c}}=317 \mathrm{~K}$, based on the results of calculations.

5. Assume the temperature of the drying air at the evaporator outlet equals its temperature at the condenser inlet, i.e., $\mathrm{T}_{\mathrm{ai} . \mathrm{f}}^{\mathrm{v}}=\mathrm{T}_{\mathrm{ai} . \mathrm{i}}^{\mathrm{c}}=317 \mathrm{~K}$.

6. Assume the absolute pressure in the evaporator is $\mathrm{P}_{\mathrm{m}}^{\mathrm{v}}=0.25 \mathrm{MPa}$. Then, according to the results of calculations based on the application of the formulae (1)-(3) using the trial method given the value of $\mathrm{X}=0$ and absolute pressure $\mathrm{P}_{\mathrm{m}}^{\mathrm{v}}=0.25 \mathrm{MPa}$, the initial temperature value for the zeotropic mixture of R600a and R601 in the evaporator of the heat pump that contains $\psi=40$ mol.\% of R600a, will be $\mathrm{t}_{\mathrm{m} . \mathrm{i}}^{\mathrm{v}}=360 \mathrm{C}\left(\mathrm{T}_{\mathrm{m} . \mathrm{i}}^{\mathrm{v}}=309 \mathrm{~K}\right)$. The value $\mathrm{X}=0$ corresponds to a state of an equilibrium system, when the mixture contains only the saturated liquid phase and, vice versa, if $x=0$ then the mixture contains only the saturated vapour phase. Similarly, determine the final temperature value of the mixture in the evaporator $\mathrm{t}_{\mathrm{m} . \mathrm{f}}^{\mathrm{v}}=540 \mathrm{C}\left(\mathrm{T}_{\mathrm{m} . \mathrm{f}}^{\mathrm{v}}=327 \mathrm{~K}\right)$ given the value of $\mathrm{X}=1$ and $\mathrm{P}_{\mathrm{m}}^{\mathrm{v}}=0.25 \mathrm{MPa}$. The temperature curve from point 4 to point 1 for the mixture containing $\psi=40 \mathrm{~mol} \%$ of $\mathrm{R} 600 \mathrm{a}$, given the absolute pressure $\mathrm{P}_{\mathrm{m}}^{\mathrm{v}}=0.25 \mathrm{MPa}$, is shown on the temperature-entropy diagram (fig. 2.)

7. After that, according to the formula (4), determine the temperature of the drying air at the outlet of the evaporator, which is $\mathrm{T}_{\text {ai.i }}^{\mathrm{v}}=332 \mathrm{~K}$ based on the results of calculations for the case of the counter-current heat exchanger. Apply the obtained values of the drying air temperatures $\mathrm{T}_{\text {ai.i }}^{\mathrm{v}}=332 \mathrm{~K} ; \mathrm{T}_{\text {ai.f }}^{\mathrm{v}}=317 \mathrm{~K}$ and the direction of the air flow to the $\mathrm{T}-\mathrm{S}$ diagram (fig. 2.)

8. For comparison, the dashed line in the diagram shows temperatures in the condenser and the evaporator of the heat pump when it runs on the working agent that consists of one substance $\mathrm{T}_{\mathrm{s} . \mathrm{mt}}^{\mathrm{c}}$; they equal, respectively, $\mathrm{T}_{\mathrm{s} . \mathrm{mt}}^{\mathrm{c}}=\mathrm{T}_{\mathrm{m} . \mathrm{i}}^{\mathrm{c}}=345 \mathrm{~K}$ and $\mathrm{T}_{\mathrm{s} . \mathrm{mt}}^{\mathrm{v}}=\mathrm{T}_{\mathrm{m} . \mathrm{i}}^{\mathrm{v}}=309 \mathrm{~K}$. 


\section{TPACEE-2016}

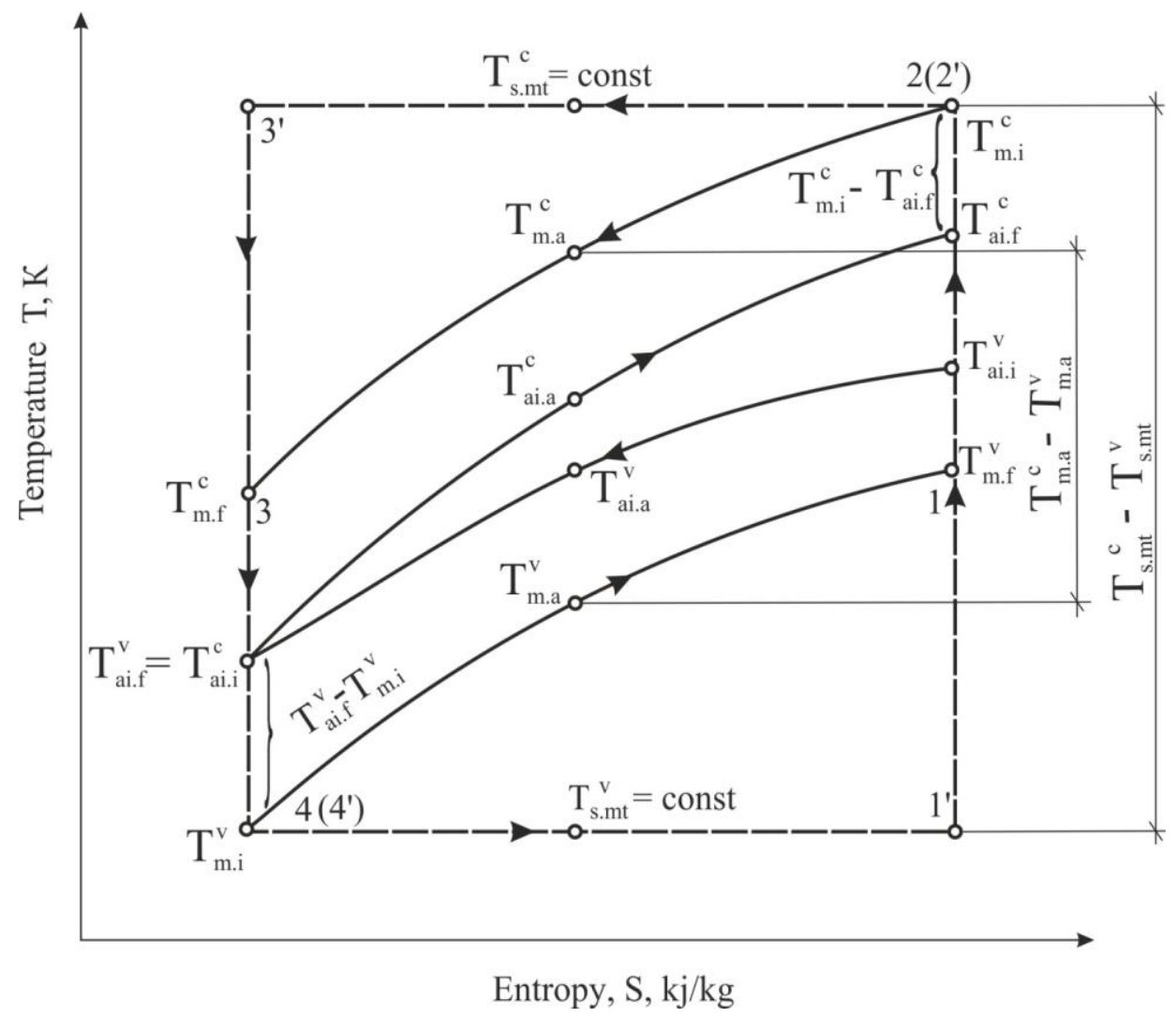

Fig.2. Comparison of a cycle 1-2-3-4-1 of the heat pump running on a mixture of R600a and R601 with a cycle $1^{\prime}-2^{\prime}-3^{\prime}-4^{\prime}-1^{\prime}$ of the heat pump running on pure R600

$1-2\left(1^{\prime}-2^{\prime}\right)$ is the vapor phase compression in the compressor; $2-3\left(2^{\prime}-3^{\prime}\right)$ is the vapor phase condensation in the condenser; $3-4\left(3^{\prime}-4^{\prime}\right)$ is throttling of the liquid phase; $4-1\left(4^{\prime}-1^{\prime}\right)$ - is boiling of the liquid phase in the evaporator.

\section{Assessing energy efficiency of the heat pump dryer}

Evaluate the effectiveness of the heat pump dryer cycle that runs on the working agent with a fluctuating temperature of 1-2-3-4-1 compared to the cycle $1^{\prime}-2^{\prime}-3^{\prime}-4^{\prime}-1^{\prime}$ for the dryer that operates on a pure working agent of R600. The real coefficient of performance of the heat pump, recommended by [24] for a preliminary assessment of these cycles, is estimated using the formula:

$\varphi_{\mathrm{r}}=\left[0.74 \cdot \mathrm{T}_{\mathrm{m} \cdot \mathrm{a}}^{\mathrm{v}} /\left(\mathrm{T}_{\mathrm{m} . \mathrm{a}}^{\mathrm{c}}-\mathrm{T}_{\mathrm{m} . \mathrm{a}}^{\mathrm{v}}\right)-\left(0.0032 \cdot \mathrm{T}_{\mathrm{m} . \mathrm{a}}^{\mathrm{v}}+0.765 \cdot \mathrm{T}_{\mathrm{m} . \mathrm{a}}^{\mathrm{v}} / \mathrm{T}_{\mathrm{m} . \mathrm{a}}^{\mathrm{c}}\right)\right]+0.9$

where $\mathrm{T}_{\mathrm{m} . \mathrm{a}}^{\mathrm{v}}, \mathrm{T}_{\mathrm{m} . \mathrm{a}}^{\mathrm{c}}$ are the average temperatures of the working agent that consists of a zeotropic mixture in the evaporator and the condenser, $\mathrm{K}$.

According to [24], in case of variable temperatures, the performance evaluation is conducted with the help of the equivalent Carnot cycle. In this case, the average temperature in the condenser $\mathrm{T}_{\mathrm{m} . \mathrm{a}}^{\mathrm{c}}$ (line 2-3) and the evaporator $\mathrm{T}_{\mathrm{m} . \mathrm{a}}^{\mathrm{v}}$ (line 4-1) are estimated, respectively: 


$$
\begin{aligned}
& \mathrm{T}_{\mathrm{m} . \mathrm{a}}^{\mathrm{c}}=\left(\mathrm{T}_{\mathrm{m} . \mathrm{i}}^{\mathrm{c}}-\mathrm{T}_{\mathrm{m} . \mathrm{f}}^{\mathrm{c}}\right) / \ln \cdot\left(\mathrm{T}_{\mathrm{m} . \mathrm{i}}^{\mathrm{c}} / \mathrm{T}_{\mathrm{m} . \mathrm{f}}^{\mathrm{c}}\right) . \\
& \mathrm{T}_{\mathrm{m} . \mathrm{a}}^{\mathrm{v}}=\left(\mathrm{T}_{\mathrm{m} . \mathrm{f}}^{\mathrm{v}}-\mathrm{T}_{\mathrm{m} . \mathrm{i}}^{\mathrm{v}}\right) / \ln \cdot\left(\mathrm{T}_{\mathrm{m} . \mathrm{f}}^{\mathrm{v}} / \mathrm{T}_{\mathrm{m} . \mathrm{i}}^{\mathrm{v}}\right) .
\end{aligned}
$$

Putting the corresponding temperature values $\mathrm{T}_{\mathrm{m} . \mathrm{a}}^{\mathrm{v}}=321.4 \mathrm{~K}$ and $\mathrm{T}_{\mathrm{m} . \mathrm{i}}^{\mathrm{c}}=340.1 \mathrm{~K}$, calculated using the formulae (7) and (8) for the cycle 1-2-3-4-1, in the formula (6), we deduce the marginal real coefficient of performance $\varphi_{\mathrm{r}}=13.3$. For the cycle $1^{\prime}-2^{\prime}-3^{\prime}-4^{\prime}-1^{\prime}-$ given the constant temperature in the evaporator $\mathrm{T}^{\mathrm{v}} \mathrm{s} \cdot \mathrm{mt}$ equal to the initial temperature of the mixture $\mathrm{T}_{\mathrm{m} . \mathrm{i}}^{\mathrm{v}}$ for the cycle 1-2-3-4-1, i.e. $\mathrm{T}_{\mathrm{s} . \mathrm{mt}}^{\mathrm{v}}=\mathrm{T}_{\mathrm{m} . \mathrm{i}}^{\mathrm{v}}=309 \mathrm{~K}$, and given the constant temperature in the condenser $T^{\mathrm{c}} \mathrm{s} \cdot \mathrm{mt}$ equal to the initial temperature of the mixture $\mathrm{T}_{\mathrm{m} . \mathrm{i}}^{\mathrm{c}}$ for the cycle 1-2-3-4-1, i.e. $\mathrm{T}_{\mathrm{s} . \mathrm{mt}}^{\mathrm{c}}=\mathrm{T}_{\mathrm{m} . \mathrm{i}}^{\mathrm{v}}=345 \mathrm{~K}$, the marginal real coefficient of performance according to the formula (6) is $\varphi_{\mathrm{r}}{ }^{\prime}=6.94$.

Thus, the marginal real coefficient of performance of compression heat pump dryers running on zeotropic mixtures that contain $40 \mathrm{~mol} \%$ of R600a, is 1.92 times higher $\left(\varphi_{\mathrm{r}} / \varphi_{\mathrm{r}}{ }^{\prime}=13.3 / 6.94\right)$ than that of the same installation operating on a pure working agent of R600.

\section{Conclusions}

1. The paper present a design of a heat pump air dryer that uses a zeotropic mixture of saturated hydrocarbons consisting of $40 \mathrm{~mol} \%$ of R600a and $60 \mathrm{~mol} \%$ of R601 as a working agent, and applies the principle of a counter-current heat exchanger with a variable temperature of both the working and the drying agents. The proposed design guarantees a reduced mean temperature difference between the air and the zeotropic hydrocarbon mixture in the evaporator and the condenser and, consequently, an increases coefficient of performance of the heat pump.

2. The correlations (1)-(3) were suggested for calculating the current temperature values of the saturated mixture of R600a and R601 of the given composition $\square$ in the evaporator and condenser of the heat pump, including the initial and final temperature values, depending on the relative amount of evaporated or condensed mixture, i.e. the vapor dryness degree $\mathrm{X}$.

3. The equations (4)-(5) were devised to estimate the initial and final values of the drying air temperature in the evaporator and the condenser of the heat pump, depending on the flow volume of the zeotropic mixture and the drying air, and temperature conditions of boiling or condensation of the mixture.

4. The correlations (6)-(8) were worked out to roughly estimate the marginal real coefficient of performance of compression heat pump dryers running on a zeotropic mixture and operating a cycle with variable temperatures in the evaporator and the condenser of the heat pump.

According to the correlations (6)-(8), the marginal real coefficient of performance of the compression heat pump dryer running on the zeotropic mixture of $40 \mathrm{~mol} \%$ of R600a, is $\varphi_{\mathrm{r}}=13.3$, which is 1.92 times higher than that of the same installation running on a pure working agent of R600 with the value $\varphi_{\mathrm{r}}{ }^{\prime}=6.94$, i.e. $\varphi_{\mathrm{r}} / \varphi_{\mathrm{r}}{ }^{\prime}=13.3 / 6.94=1.92$. 


\section{Acknowledgements}

This work has been prepared with the support of the "Yuri Gagarin State Technical University of Saratov" and Public Limited Company "Giproniigaz".

\section{References}

1. D. Reay, D. Macmichael, Heat Pumps, Design and Applications, translation from English (Energoizdat, Moscow, 1982)

2. E.I. Yantovskiy. L.A. Levin, Industrial Heat Pumps (Energoatomizdat, Moscow, 1989)

3. International Simposium on the Industrial Application of the Heat Pump (1982)

4. V.G. Gorshkov, Heat Pumps, Analytical review, An industrial equipment guide, 2, 4780 (2004)

5. O.Sh. Vezirishvili, G.I. Chogovadze et al., Teploenergetika, 12, $45-47$ (1981)

6. B.N. Kuritsin, Fundamentals of energy saving in heating and ventilation technology (Publishing house Nadezhda, Saratov, 1996)

7. P.D. Lebedev, Calculation and design of the drying equipment (Gosenergoizdat, Moscow-Leningrad, 1973)

8. E.V.Romanova, A.Yu. Orlov, Vestnik of Tambov State Technical University, 14(3), 591-596 (2008)

9. V.I. Konovalov, E.V. Romano)va, N.Ts. Gatapova, Vestnik of Tambov State Technical University, 17(1), 153-178 (2001)

10. The Montreal Protocol on Substances That Deplete the Ozone Layer, adopted by the government of the USSR in November (1988), enacted on January 1 (1989)

11. The Kyoto Protocol to the United Nations Framework Convention on Climate Change. Ratified by the Federal Law of the Russian Federation N 128-FZ of November 4 (2004) It came into force on February 16 (2005)

12. A.M. Kutepov, L.S. Sterman, N.G. Styushin, Hydrodynamics and heat transfer in vaporization: a textbook for universities (Vysshaya shkola, Moscow, 1977)

13. M.A. Mikheev, I.M. Mikheeva, Foundations of heat transfer (Energiya, Moscow, 1973)

14. A.P. Usachev, A.V Rulev, Teplovye processy v tehnike, 5(8), 343-353 (2013)

15. SP 42-101-2003). General provisions for the design and construction of gas distribution systems made of metal and plastic pipes, Stroyizdat, Moscow (2003)

16. PB 12-529-03 Safety rules of gas distribution and gas consumption systems, JSC STC Industrial Safety, Moscow (2003)

17. N.I. Preobrazhenskiy. Liquefied gases (Nedra, Leningrad, 1975)

18. N.L. Staskevich, D.Ya. Vigdorchik, Handbook of liquefied petroleum gases (Nedra, Leningrad, 1986)

19. M.Kh. Karapetyants, Chemical thermodynamics (Khimiya, Moscow, 1975)

20. A.P. Usachev, A.L. Shurayts, A.V. Rulev, T.A. Usacheva, System research on increase of heat exchange intensity of liquefied petroleum gas regasificators (Saratov State Technical University, Saratov, 2010)

21. B.N. Kuritsin, A.P. Usachev, B.P. Bogdanov, The use of gas in the national economy: collection of articles of the Griproniigaz institute (Saratov University Publishing House, Saratov, 1974)

22. M.D. Tilicheev, Physicochemical properties of individual hydrocarbons (Gostoptehizdat, Moscow-Leningrad, 1947)

23. C.H. Nysewander, B.H. Sage, W.N. Lesey, Industrial and Engineering Chemistry, 32(1), 118-123 (1940)

24. V.S. Martynovskiy, Cycles, schemes and characteristics of thermotransformers (Energiya, Moscow, 1979) 